Gonzales Fernández, Guissela (2019). Tengo el color mismo de mi Madretierra. Rito Andino y decolonialidad en la poética de Efraín Miranda Luján. Lima: Universidad Nacional Mayor de San Marcos, Universidad Nacional del Altiplano, Latinoamericana Editores.

El análisis que en este libro realiza la autora, acucioso y lúcido, tiene dos anclajes fundamentales en términos metodológicos: la semiótica y la hermenéutica. Semiosis y hermenéusis nos indican que se estudia el objeto de trabajo en su dimensión estrictamente literaria y como fenómeno sociocultural. El trabajo está conformado por un texto introductorio, cinco capítulos y conclusión.

En el texto introductorio la autora establece los elementos teóricometodológicos en los que se va a sustentar el análisis y precisa la terminología referente, evidenciando su perspectiva epistemológica. En tal sentido, arma un andamiaje que imbrica el pensamiento de autores como Walter Mignolo, Antonio Cornejo Polar, Raúl Bueno, Víctor Turner, Ángel Luis Luján, Aníbal Quijano, Wayne Booth y Oswald Ducrot. Define conceptos categoriales como los de: "pensamiento desde el borde", "horizonte de sentido" y "semiosis decolonial". También, en este apartado, se hace una síntesis capitular y se define que: "la propuesta central de este estudio es que Choza puede ser entendida como una Semiosis decolonizadora" (p. 31). Debemos hacer notar la declaración de principios hecha por la autora desde su condición de "investigadora inmersa en el universo cultural de occidente" (p. 25), aludiendo a las limitaciones que ello implica para su quehacer crítico. También, a lo largo de esta introducción, queda esbozado el perfil poético e histórico de Efraín Miranda Luján.

En el capítulo primero, "Efraín Miranda y los poetas de la generación del 50", con el fin de ubicar al autor de Choza en el horizonte del quehacer poético nacional y regional andino, se establecen dos escenarios: el de la emblemática generación del 50 y el de la poética puneña de ese momento. Con este fin, la autora retoma el concepto de "campo", propuesto por Bourdieu, y las categorías de "totalidad contradictoria" y "heterogeneidad" formuladas por Cornejo Polar. Se indaga, asimismo, en las problemáticas que implica nominar la generación del 
50, así como la definición del corpus poético que comprende; revisa la crítica en torno a dichos poetas, el marco sociocultural en que realizan su trabajo y la actitud de estos frente a su realidad. Al abordar "el campo poético puneño de la década del 50", siguiendo a Antonio Cornejo, hace un llamado a repensar la historia literaria del Perú, de manera que sea incluyente respecto de "las manifestaciones que se alejan de las corrientes del centralismo limeño" (p. 60). En el caso de la poesía puneña sigue la misma estrategia de reflexión, examinando el proceso crítico que se ocupa de ella y ensaya la posibilidad de su sistematización. Al cierre del capítulo apunta que Efraín Miranda, para la crítica limeña que se ocupa de la generación del 50 , es prácticamente un poeta inexistente, mientras que para los puneños es figura relevante.

El capítulo segundo, "Singularidad poética de Efraín Miranda: de Muerte cercana (1954) a Choza (1978)", la autora nos presenta una premisa central: la singularidad poética de Miranda, distanciada tanto del quehacer poético central limeño como de la producción puneña, y propone que "es posible hallar cierta continuidad entre los poemarios Muerte cercana y Choza" (p. 77). Para demostrarlo, confronta las lecturas críticas que se produjeron entre los años de 1954 a 1959 por parte de autores como Sebastián Salazar Bondy y Washington Delgado, con la crítica actual de estudiosos como Elton Honores y Marco Martos. La autora centra su análisis en la perspectiva de la recepción. En este proceso, tomando la categoría de "sujeto migrante", concluye el capítulo con la afirmación de que entre Muerte cercana y Choza el hilo de continuidad que se tiende consiste en mostrar "la crisis de un sujeto frente a una modernidad impuesta" (p. 118).

El capítulo tercero del libro, "Situación enunciativa en Choza desde los intersticios de la decolonialidad", toma como su motivo central el acto enunciativo. Orienta la reflexión desde las propuestas teóricas de la pragmática lingüística. Los conceptos de "polo de la emisión" y "polo de la reflexión”, desarrollados por Luis Ángel Luján Atienza, sirven como vectores para esclarecer los locus enunciativos presentes en Choza. El sentido de este análisis desemboca en el proceso de decolonialidad, pasando por las categorías de "memoria" y "testimonio", para 
reafirmar lo que ya se había expuesto anteriormente: la particularidad de la poética de Miranda, pero aquí a través de la construcción del "locus enunciativo geopolítico decolonizador", el cual — añade la autora-, "propone una forma de poetizar, que estéticamente y epistemológicamente, se aleja de los paradigmas occidentales y se distancia de las poéticas peruanas de las décadas del $50 \mathrm{y}$ del 70” (p. 154).

Los capítulos cuarto y quinto se centran en un análisis semiótico de Choza. El primero de ellos se titula: "Semiosis decolonizadora: rito de paso, ciclicidad andina y reordenamiento de la pacha"; mientras que el segundo lleva como título: "Propuesta para una aproximación a la Semiosis decolonial andina de Choza". A través de este análisis sígnico del discurso poético de Miranda, se resalta el sistema de códigos que emana del pensamiento andino (episteme y sensibilidad), indispensables de comprender y de insertar como elementos de análisis de textos como los que conforman la obra poética de Efraín Miranda. Guissela Gonzales concluye resaltando el valor de la poesía contenida en Choza como expresión de la "condición humana" que "muestra la fuerza viviente y vigente de la cultura andina".

Tengo el color mismo de mi Madretierra. Rito andino y decolonialidad en la poética de Efraín Miranda Luján, es un trabajo que evidencia un rigor investigativo absoluto, perfectamente argumentado y estructurado de tal manera que todas sus partes integran una experiencia de conocimiento que, desde el análisis del poemario, le lleva al lector a contemplar el mundo andino de Miranda como una "otredad" cultural en conflicto con el eurocentrismo determinante de las metrópolis (la peruana y por ende las de toda Latinoamérica), pero que nos demanda su conocimiento para la comprensión integral del Ser latinoamericano en sus dimensiones literarias e históricas.

Este libro es, de muchas maneras, un aporte altamente significativo de los estudios literarios, realizados en el ámbito universitario, que con intenso esfuerzo y grande conocimiento reduce un tanto la deuda que su autora señala: la del acercamiento crítico a la obra de Miranda. Así, puede afirmarse que el trabajo 
de Guissela Gonzales es una respuesta al reclamo que Antonio Cornejo Polar hizo con respecto al quehacer crítico latinoamericano en los rubros de: rigor científico y metodológico, adecuación a la peculiaridad de la literatura latinoamericana e integración al proceso de liberación social. Por todo lo anterior, este libro no solo es pertinente y fundamental para los estudios literarios del Perú, sino que lo es de manera sustantiva para los estudios literarios en general, ya que su metodología y sobre todo su objeto de estudio tienen un valor incuestionable en el ámbito universal de la literatura.

\section{Rolando Álvarez}

Universidad de Guanajuato, Guanajuato, México.

Contacto: jr.alvarez@ugto.mx

https://orcid.org/0000-0003-1741-9708 